\title{
The Importance of Data Warehousing for Community Development Organisations: The Impact on Iraqi Victims of the Explosive Remnants of War
}

\author{
Ahmed Hassin \\ Australian Red Cross Blood Service, Australia
}

\begin{abstract}
This article discusses how important data warehousing is for development organisations. Data warehousing is a great asset for organisations to plan and prioritise their interventions for helping victims of war remnants. The article shows how information should be of high quality and accounted for. Information extracted from data warehouses can be used to show the impact of intervention on beneficiaries. It also enables more effective stakeholder interaction. Data warehousing assists organisations to gain a competitive advantage by providing good services to beneficiaries and, will, consequently, help organisations to attract donor funds. The example given from Iraq shows how Iraqi Health and Social Care Organisation used a data warehouse to identify needs, plan projects and raise funds for survivors of explosive remnants of war. This concept can be used by other development and aid organisations operating in countries affected by explosive remnants of war and health related development fields.
\end{abstract}

\section{Keywords}

Data warehousing, Iraq, Victims of Explosive Remnants of War, Information Systems, Development Organisations, IHSCO

\section{Introduction}

In today's highly turbulent, extremely competitive environment, development organisations face considerable pressure to meet or exceed donor/beneficiary expectations by delivering high quality services and innovative ideas. In order to be effectively responsive to needs, organisations should be utilising the enormous wealth of digital information available nowadays. As a very valuable and most effective part of organisations, information technology infrastructure plays a key role in the success or failure of delivery of services. Data warehousing have been proved to be an extremely useful and effective resource in many business applications and can lead organisations gaining a competitive advantage (Rundesteiner et al, 2000).

Data warehouses provide vital information which can be used as a foundation for effective interventions; being the right organisation in the right time with the right intervention (Chenoweth et al,

Copyright $@ 2008$ Victoria University. This document has been published as part of the Journal of Business Systems, Governance and Ethics in both online and print formats. Educational and non-profit institutions are granted a nonexclusive licence to utilise this document in whole or in part for personal or classroom use without fee, provided that correct attribution and citation are made and this copyright statement is reproduced. Any other usage is prohibited without the express permission of the
2006). Effective management information systems are based on data warehousing which increases the available data and decreases costs by avoiding redundant data entry (Juntilla et al, 2007). Information technology (IT) is considered an important partner to other resources of the organisation in implementing business strategies. It is important to see an integrated framework for aligning IT applications across various functional areas with operations strategy 
(Kathuria et al, 2007). Successful organisations should be equipped with effective IT solutions and management information systems (MIS) necessary to achieve the strategy objectives. IT is a stimulus to effecting transformational change in development fields directly impacting on people's lives (Tansley et al, 2001) and Iraq is an explicit example. Iraqi National Mine Action Authority (NMAA) estimates that some 13 million people are affected by unexploded ordnance (UXO) and some 7.5 million are affected by landmines. Iraq's total population is estimated at 26 million. However, there is no comprehensive or systematic nationwide data collection mechanism and data management system for explosive remnants of war (ERW) casualties in Iraq (MAC, 2005). From the perspective of ERW victims/survivors, such a system in place is vital for identifying their needs in particular areas. This should lead to set priorities, adapting or introducing new programmes to meet the needs and rights of ERW survivors (UNIDR, 2005). The management of provision of service for the survivors relies on information and reports produced after collection of relevant data. Effective management of such information will assist in the development and government organisations assess survivors' needs and will result in deciding the right intervention (Juntilla et al, 2007).

This study discusses the importance of data warehousing for aid and development organisations. I have picked a sample of a non-profit development organisation from Iraq where the operations environment for humanitarian organisation is extremely challenging. I will try to examine the impact of data warehousing on decision-making for interventions related to victims of explosive remnants of war. The study will discuss how data warehousing is a great tool to gain competitive advantage.

\section{Background of the Problem}

Landmines, unexploded cluster bomb-lets and abandoned unexploded ordnance left over after a conflict continue to severely affect many countries. Iraq ranks high among the countries most severely contaminated by landmines and explosive remnants of war (ERW). This is a legacy of internal conflicts between the Kurds and central governments, the 1980-1988 war with Iran, the 1991 first Gulf War after Iraq's invasion of Kuwait, and the ongoing conflict and military operations began with the invasion of Iraq by US-led Coalition forces in March 2003 (MAC, 2006). Since then, large amounts of explosive remnants of war (ERW) such as artillery shells, , cluster bomb-lets and other sub-munitions, have been abandoned in urban and rural residential areas or nearby. Such practices have been causing an everincreasing number of ERW victims (Kim, 2003). The term "Explosive Remnants of War (ERW)" is used "to describe the explosive threat to the community in a region at the end of a conflict or at the beginning of a period of stability" (GICHD, 2002). In Iraq, a data-sharing system was established in the second half of 2004 with all stakeholders, including the Ministry of Health. Some data were handed over to the National Mine Action Authority. Nevertheless, limited casualty data is available due to insecurity, a lack of political will, and the absence of a comprehensive data management system. One of challenges for planning mine action interventions is the lack of victim data (MAC, 2006).

There are various sources of information on new casualties including media reports, surveys, assessments, government and hospital records, and databases. In principle, it is the responsibility of national governments to monitor the health and well-being of their population. However, in practice, many countries do not have the capacity to maintain a coordinated casualty data collection system (UNIDR, 2005); and Iraq, in its current situation, is one of those countries. National and international efforts have been working on revitalising and strengthening data collection capacity in Iraq; and to establish a national casualty surveillance system and database (MAC, 2006).

\section{Theory and Literature Review}

The issue of the rehabilitation and reintegration of explosive remnants of war survivors is seen as an integral component of the broader context of development in Iraq (Maes, 2007). Those dedicated to helping these victims must first create a means of keeping track of the number of victims and the nature of their injuries. Their second concern is finding a secure way in which to deliver appropriate assistance; whether physical or socio-economic (Kim, 2003). Data Warehousing is now a well-established part of 
the business world. (Delve and Allen, 2001). However, at present, only a limited number of ERW affected countries use a comprehensive database, and few of them are able to provide full year data or data collected in all ERW affected regions (UNIDR, 2005). The direct impact on the community in terms of potential casualties can only be quantitatively assessed if there is sufficient data available to populate a model (GICHD, 2002). Many countries have some statistics about ERW casualties but such data fail to highlight the humanitarian and socio-economic impact of ERW on the population. Experience from other countries proved that lack of updated information about ERW victims is a serious challenge in planning interventions like risk education and assistance programmes (Perlstien, 2008). In the discussions of ERW risk education and victim assistance, we are confronted with the problem of uninformative impact figures. In both cases, it is the long-term quality of the intervention that is important, rather than figures on numbers of people who have received physical rehabilitation or a mine risk education (Harpviken, 2003). Data warehouses provide cross-functional information that allow organisations to understand what is happening and how. By taking victim data from mine risk education or victim assistance aspects and analysing the trends and correlations, organisations can get great value to plan interventions and measure impact upon implementation (Gardner, 1998).

Data collection using epidemiological surveys is essential for an in-depth understanding of the number of target groups and for a comprehensive assessment of their needs. The results of such studies facilitate the allocation of resources and aid in evaluating the impact of interventions (Cobey and Ayotte, 2000). In order to deliver health-related services, epidemiologists and other public health professionals need low cost and easy-to-use data warehouse to manage data, perform data analysis, and map results (Dean, 1999). A data warehouse can cope with data in a variety of formats from diverse sources, and also data which have been summarised (Delve and Allen, 2001) making interaction with stakeholders easier. Essentially, a data warehouse provides historical data for decision support applications. Such applications include reporting, executive information systems, and data mining (Gagnon, 1999).

Data Warehousing involves the acquisition of data from various internal and external sources and the management of this data in an integrated database. Flexible reporting and analysis tools are provided for business users to extract timely and accurate information to support their managerial and decisionmaking process (Ferguson, 1997). The underlying reasoning behind the notion of a data warehouse is, "creating a central corporate data architecture geared towards responsive management decisionsmaking" (Kelly, 1994). Today's evolving health care environment requires improvements in how information is processed, distributed, analysed, and used (Waldo, 1998). Relevant information extracted from data warehouses can help organisations understand business needs and the potential of meeting such needs. This information can, also, be used as an indicator to measure the success of certain tasks implemented by business and operation units of the organisation (Chenoweth et al, 2006).

Effective management information systems help the organisation's operations strategy to be implemented effectively and help the organisation to gain competitive advantage. Hill's (2006) influential methodology for market order-winners and qualifiers is very important for organisations to consider before moving on to a discussion of operational processes and infrastructure. The attainment of competitive advantage requires the interaction of information systems (IS) with the structure, human resource management, technology and logistic systems. It is important to see an integrated framework for aligning information technology applications across various functional areas with operations strategy (Kathuria et al, 2007). However, we need to take into consideration the challenge to have a fully operative and productive IS in non-stable developing countries with low level of industrialisation and basic service (Prasad et al, 2003).

\section{Data Quality Assurance}

The information system may contain huge amounts of data sets each. As the number of data items per record increases, determining errors in these data items or erroneous combinations of data item values becomes quite difficult (Paradice and Fuerst, 1991). As data bases are used for decision-making purposes, data warehouses should be accounted for to meet the demands they were created for. Without 
such accountability, organisations may not receive credible information produced from data warehouses. This will lead to organisations losing their competitive advantage that data warehouses provide business with (O'Leary, 1999). Therefore, the importance of data quality in management information systems (MIS) increases daily. As organisational information systems increase in use, cost, and complexity, the quality of the data upon which decisions are based becomes critical. Erroneous data may lead to decisions and actions that have severe consequences (Waldo, 1998).

\section{Iraqi Health and Social Care Organisation's (IHSCO) - an example}

Since March 2003, some national and international organisations have been gathering data on new casualties. One of the sources of this information is Iraqi Health and Social Care Organisation (HI, 2006). Iraqi Health and Social Care Organisation (IHSCO) were established in 2004 to serve the Iraqi society and, specifically, people with disability (IHSCO, 2004). Since it was established in February 2004, Iraqi Health and Social Care Organisation (IHSCO) have been working on disability issues and projects across Iraq. Being a local pioneer non-profit non-governmental organisation in this field, IHSCO depend on data gathered from the field to design projects and then to measure the performance and outcomes of the project. Therefore, data collection has been a pillar of each of the following organisation's activities:

- Surveys on communities and people affected by Explosive Remnants of War,

- Rehabilitation and reintegration of people with disability,

- Awareness-raising and education programmes to prevent causes of disability.

IHSCO set up a war victim surveillance system in mid-2004. Since early 2006, retrospective data collection focused on ERW casualties occurring after March 2003 in six central and southern governorates.

The objectives of this initiative by IHSCO were:

" - define the scale of the problem

- define the needs and priorities for de-mining

- $\quad$ highlight groups and behaviours to target for Mine Risk Education

- contribute to evaluating the effectiveness of de-mining and MRE programmes

- $\quad$ raise awareness about the impact of mines/UXO on society

- $\quad$ provide an initial understanding of the needs of mine and UXO survivors" (IHSCO, 2006).

IHSCO adopted a strategic decision for casualty data warehousing by establishing a populated database which can report statistics and analyses of Explosive Remnants of War (ERW) victims. Information from that data warehouse can be utilised to design and implement victim assistance and awareness programmers for communities affected by ERW. That option was with external technical support provided for free by the Centers for Disease Control and Prevention (CDC), USA. CDC developed a casualty database for IHSCO purposes based on CDC's Epi-Info Database and trained IHSCO data management staff members. With Epi-Info ${ }^{\mathrm{TM}}$ and a personal computer, epidemiologists and public health professionals can rapidly develop a questionnaire or form, customise the data entry process and enter and analyse data (CDC, 2008)

IHSCO also developed its quality assurance systems to guarantee the accuracy of the data gathered. That was done through checking data at three stages before entry into the database. The data management flow chart below exhibits the current system maintaining set quality assurance standards.

Data were collected from the field by interviews with victims of ERW or their families using a questionnaire form. The data collected are entered into the Epi-Info database which produces the analyses and reports reflecting the findings of the research.

As an example, IHSCO analysis of data using EPI-INFO data recorded between March and June 2006 indicates that 148 of 193 casualties (77 percent) were due to cluster munitions (compared to 26 antipersonnel mine casualties); including 40 killed and 108 injured (HI, 2006). 

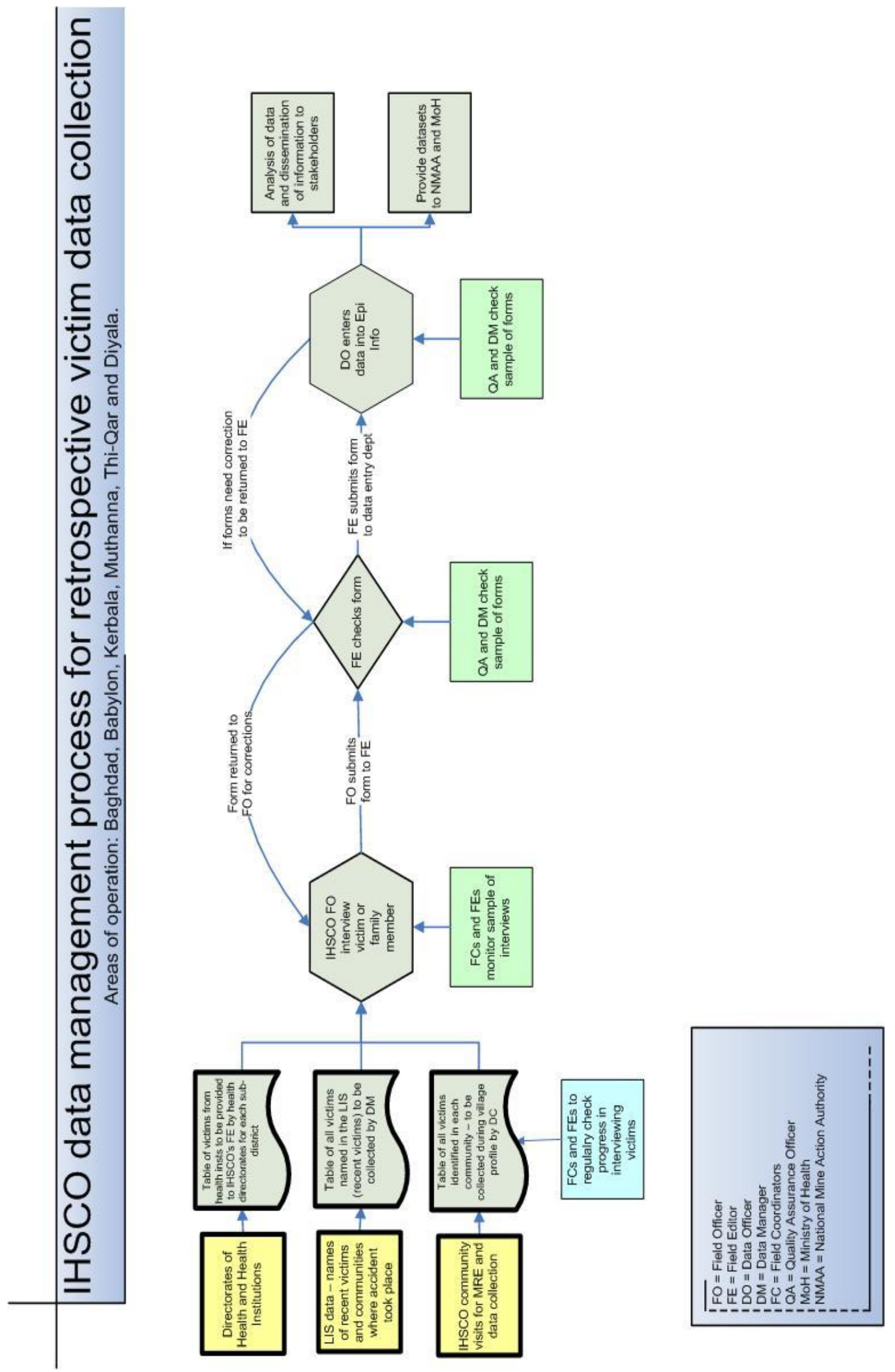

Figure 1: IHSCO data management flow chart 


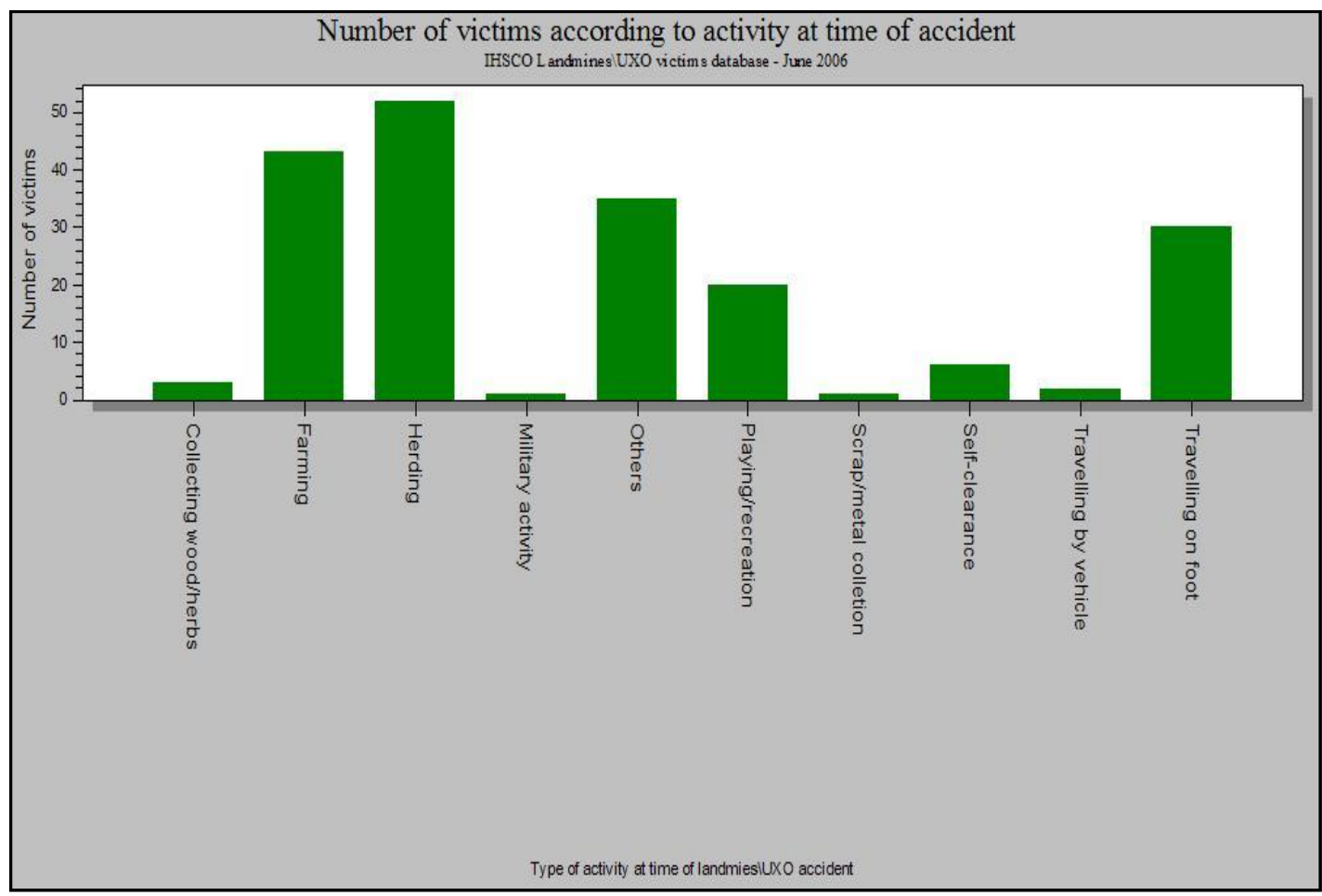

Figure No. 2

IHSCO data were processed and reports were disseminated to stakeholders, which was useful for planning for prevention and assistance activities and projects by IHSCO itself and other stakeholders. The data warehouse is able to produce representative information about many aspects related to victims, such as: age group, cause of accident, activity at time of accident, type of explosive device, victim demographics, geographic presence and other useful statistics.

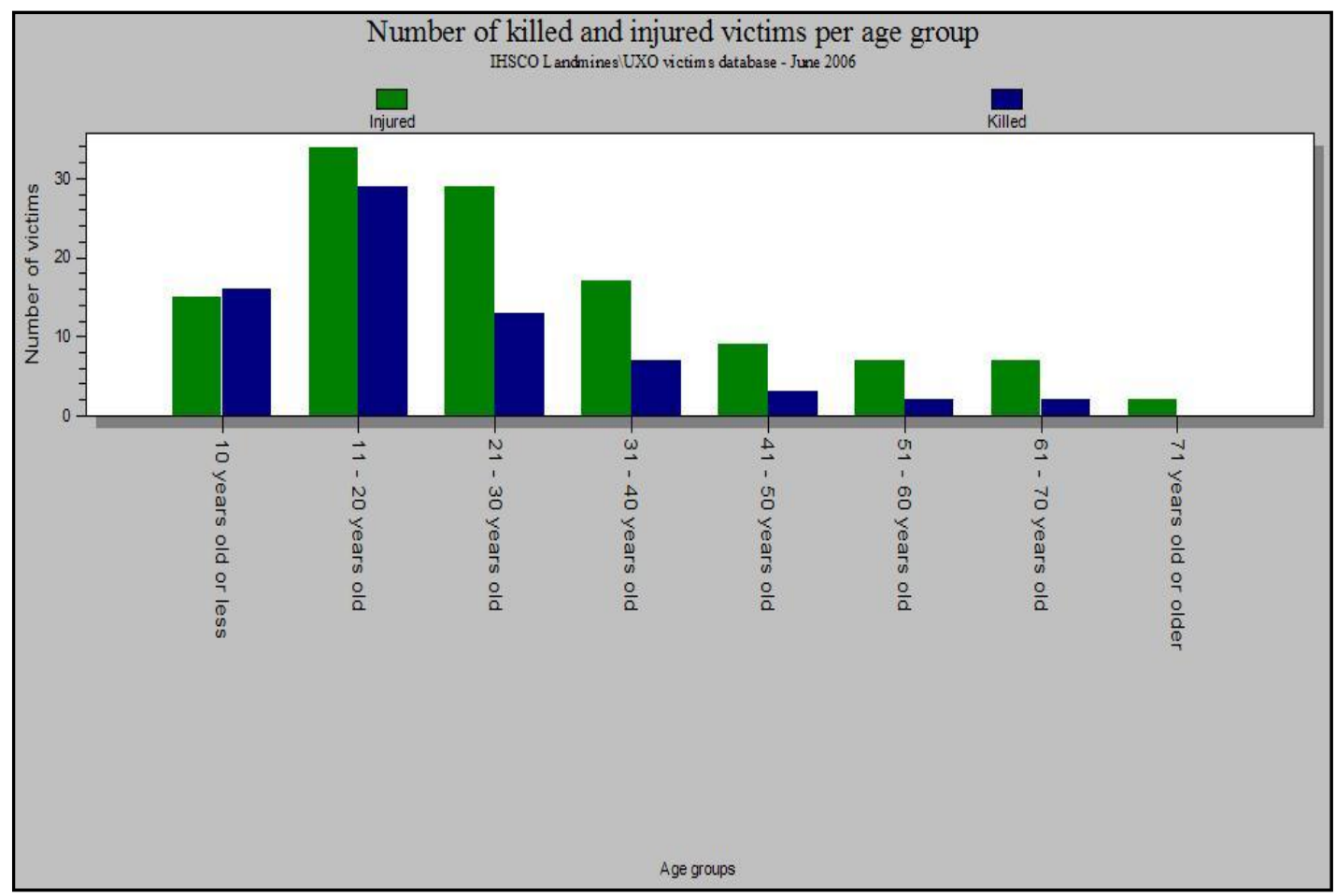

Figure No. 3

It is very a handy tool for organisations working with ERW survivors to understand the context in order to be able to provide service. Moreover, it will result in more business opportunities in terms of 
planning and designing new projects related to disability issues. IHSCO used its data to develop projects and appeals for vulnerable and affected people and communities. Such appeals were for prevention and victim assistance project in central and southern parts of Iraq in 2007 and 2008 (E-MINE, 2007).

\section{Conclusion}

This paper has shed light on some key advantages organisations can obtain from having a data warehouse. Development organisations dealing with ERW victims operating in Iraq, or elsewhere, should consider data warehousing about survivors. Literature suggests that in order to have effective provision of service to target certain groups, organisations should have a reliable source of information. This can be done through data warehousing. Data warehousing is a critical success factor for organisations to make the right decisions with regards to interventions. It is also vital for coordination of those interventions amongst stakeholders. Organisations that have functional data bases can gain a competitive advantage as they know what they want to do, when, where and how. IHSCO's experience shows that its data warehouse was used as an effective marketing tool to raise funds for its projects. Information were also useful for other stakeholders for many humanitarian purposes. Information generated by the database can be used by organisations and donors to measure the impact of intervention on beneficiaries. Data collected need to be on high quality levels, and organisations must maintain accountable quality assurance systems in place.

\section{References}

CDC (2008). What is EPI-INFO?, http://www.cdc.gov/epiinfo/. September 2008, Centers for Disease Control and Prevention.

Chenoweth T., Corral K. \& Demirkan H., (2006), "Seven Key Interventions for DATA WAREHOUSE SUCCESS", Communication of the ACM, Vol. 49, No.1, 114-119

Cobey J. and Ayotte B, 2000, "Tools to measure landmine incidents and injurie", THE LANCET, Vol. 355 , pp 1549-1550

Dean A., 1999, "Epi Info and Epi Map: Current Status and Plans for Epi Info 2000", Journal of Public Health Management and Practice, pp 54-56

Delve J and Allen M, 2001, "Large-Scale Integrated Historical Projects Does Date Warehousing offers any scope for their creation and analysis?", History and Computing, pp. 301-313

E-MINE (2008), 2008 Portfolio of Projects, http://www.mineaction.org/projects funding.asp $? \mathrm{aa}=139 \& \mathrm{c}=\& \mathrm{sh}=\% 2 \mathrm{C}$ November 2008, Electronic Mine Information Network

Ferguson N, 1997, "Data Warehousing", International Review of Law Computers \& Technology, Vol. 11, pp 243-249.

Gagnon G., 1999, "Data warehousing: an interview", PC Magazine, 9, pp 245-246.

Gardner S., (1998), "Building the Data Warehouse”, Communications of the ACM, Vol. 41, No.9, 5260

Geneva Centre for Humanitarian Demining (2002), Explosive Remnants of War (ERW) A Threat Analysis.

Harpviken K.B, 2003, “Guides to humanitarian mine action”, Third World Quarterly, Vol. 24, pp 967976

HI (2006), 'Fatal Footprint: The Global Human Impact of Cluster Munitions', 2006, Preliminary Report. http://www.mineaction.org/downloads/1/Fatal Footprint HI report on CM casualties.1.pdf November 2006. Handicap International

Hill T., 2000, Manufacturing Strategy Text and Cases, $2^{\text {nd }}$ edition

IHSCO (2004), Final Report of the Iraqi Health and Social Care Organisation For year 2004, http://ihsco.org/reports.html. 2007, Iraqi Health and Social Care Organisation

IHSCO (2006), Protocol for IHSCO's collection of landmine and UXO victim data 2006

Juntilla K., Meretoja R., Seppala A., Tolppanen EM., Ala-Nikkola T. \& Silvennoinen L., (2007) "Data warehouse approach to nursing management", Journal of Nursing Management, 15, 155-161 
Kathuria R., Joshi M. P. and Porth S. J., 2007, Organizational alignment and performance: past, present and future, Management Decision Vol. 45 No. 3, pp. 503-517

Kelly S, 1994, "Data Warehousing: the Route to Mass Customization", John Wiley \& Sons.

Kim K, 2003, "Victim Assistance in Iraq", Journal of Mine Action, vol. 7, P.1.

MAC (2005) 'Landmine Monitor Annual report 2005: toward a Mine-Free World'. http://www.icbl.org//m/2005/ October 2005, Mines Action Canada.

MAC (2006), 'Landmine Monitor Report 2006: Toward a Mine-Free World', http://www.icbl.org/lm/2006/ July 2006, Mine Action Canada

Maes K. (2007), "The Human Impact of Cluster Munitions", Humanitarian Exchange Magazine. http://www.odihpn.org/report.asp?id=2872

O'Lear D, (1999), "Real D: A Schema for Data Warehouses", Journal of Information Systems, Vol. 13, No.1, 49-62

Paradice D.B and Fuerst W.L, 1991,"An MIS Data Quality Methodology Based on Optimal Error Detection", Journal of Information Systems, pp 48-50.

Perlstein A. (2008), " ERW and Survivor Assistance in Central Vietnam”, Journal of Mine Action, Mine Action Information Center, http://maic.jmu.edu/journal/12.1/focus/perlstein/perlstein.html

Prasad S. and Sounderpandian J., 2003, Factors influencing global supply chain efficiency: implications for information systems. Supply Chain Management: An International Journal, vol. 8, No.3, pp.241250 .

Rundesteiner E.A, Koeller A \& Zhang X., (2000), "Maintaining Data Warehouses Over Changing Information Sources", Communications of ACM, Vol 43, No. 6, 57-62

Tansley C., Newell C., Williams H., 2001, Effecting HRM-style practices through an integrated human resource information system An e-greenfield site? Personnel Review, Vol. 30 No. 3, pp. 351-370.

United Nations Institute for Disarmament Research, 2005, "Humanitarian Perspectives to Small Arms and Explosive Remnants of War".

Waldo B, 1998, "Decision Support and Data Warehousing Tools Boost Competitive Advantage", Nursing Economics, Vol.16, pp 91-93. 